\title{
Vulvar High Grade Squamous Intraepithelial Lesion
}

National Cancer Institute

\section{Source}

National Cancer Institute. Vulvar High Grade Squamous Intraepithelial Lesion. NCI

Thesaurus. Code C4761.

An intraepithelial lesion of the vulvar squamous epithelium that carries a significant clinical risk of invasive cancer development if not treated. Almost all these lesions contain HPV16. (WHO, 2014) 